\title{
Factors associated with the rapid implementation process of the fixed-dose combination RHZE tuberculosis regimen in brazil: an ecological study
}

\author{
José Ueleres Braga ${ }^{1,2^{*}}$, Deborah Araújo da Conceição ${ }^{2}$ and Anete Trajman³
}

\begin{abstract}
Background: The Brazilian National Tuberculosis Control Program (NTCP) recommended the fixed-dose four-drug combination (FDC-RHZE) regimen to treat new tuberculosis cases in December 2009, expecting to increase adherence and avoid resistance. We evaluated factors associated with the speed of the new regimen implementation process in this continent-sized country.
\end{abstract}

Methods: We conducted an ecological study based on the Brazilian Case Notification Database (SINAN) having the Brazilian municipalities as the analytical unit. Municipalities with at least one case reported from December 2009 to March 2011 were considered eligible. The association of rapid ( $\leq 3$ months) implementation of the new regimen with demographic, epidemiological and operational health service characteristics, such as compliance with NTCP recommendations (supervised treatment, bacteriological confirmation of the diagnosis and monthly bacteriological monitoring), was analyzed. We used the adjusted odds ratios (OR) and their $95 \%$ confidence interval (Cl) to assess the association of independent variables with the outcome in a multiple logistic regression model.

Results: Rapid implementation of the new regimen in municipalities was associated with small populations ( $\mathrm{OR}=25.5,95 \% \mathrm{Cl}=19.1-34.1)$, low population density $(\mathrm{OR}=2.3,95 \% \mathrm{Cl}=1.9-2.9)$, low tuberculosis incidence rates ( $\mathrm{OR}=8.8,95 \% \mathrm{Cl}=6.7-11.4)$ and good compliance with other NTCP recommendations.

Conclusions: We showed that SINAN secondary data analysis is feasible and useful to learn lessons from. Municipalities with high tuberculosis burden and large populations need special attention for implementing new recommendations. This is particularly important considering the Global Alliance pipeline for new tuberculosis treatment regimens.

Keywords: Tuberculosis, Drug combinations, Health plan implementation, Epidemiology, Public health

\section{Background}

In 1996, the Brazilian National Tuberculosis Control Program (NTCP) incorporated the directly observed treatment strategy (DOTS) for reaching World Health Organization (WHO) cure targets and reducing default rates, thus preventing emergence of resistant bacillus [1]. In the following years, as in other countries that recommended DOTS, a decrease in default rates and an increment in case detection and cure rates were observed in Brazil. Nevertheless, this

\footnotetext{
*Correspondence: veleres@gmail.com

'Professor Helio Fraga Reference Center, National School of Public Health,

Fiocruz, Rio de Janeiro, Brazil

${ }^{2}$ Social Medicine Institute, Rio de Janeiro State University, Rio de Janeiro, Brazil

Full list of author information is available at the end of the article
}

was insufficient to achieve the target for tuberculosis control in the country $[2,3]$.

By the end of 2009, Brazil was the only high-burden country to use a treatment regimen with only three drugs [fixed-dose combination (FDC)-Rifampin and Isoniazid $(\mathrm{RH})$ and Pyrazinamide (Z)]. Despite a free-of-charge treatment, the default rates were around 9.3\%, attaining $14 \%$ in some states [4]. At this point, the NTCP advisory board revised the Brazilian Tuberculosis Guidelines and recommended the WHO-suggested four-drug FDC regimen for tuberculosis treatment for adolescents and adults (over 10 years old). Besides including Ethambutol (E), the new regimen reduced doses of $\mathrm{H}$ (from 400 to $300 \mathrm{mg}$ ) and of $\mathrm{Z}$ (from 2000 to $1600 \mathrm{mg}$ ). The new FDC-RHZE

\section{Biomed Central}


regimen was expected to result in lower default rates and higher effectiveness of treatment. The rational was that the smaller number of pills to be taken and the better tolerance due to dose reduction would increase adherence to treatment [5]. Finally, the NTCP expected that the inclusion of a fourth drug would fight the emergence of resistance, which was, at that point, widely spread in Eastern Europe, Asia and Africa [6].

According to the Brazilian Ministry of Health (MoH), the implementation of the FDC-RHZE regimen has followed a schedule set by the NTCP in agreement with the Brazilian states' programs [5]. The use of this regimen started in the North (Amazonian) region, which had the highest incidence rate until the 90's, while the Southeast region, presently with the highest disease burden, was the last one to implement the new regimen [7]. The effective use of the new regimen may have faced important barriers in healthcare services, such as poor adhesion by professionals and by tuberculosis patients.

New tuberculosis treatment regimens and diagnostic technologies in the health system are expected during the following years [8-12]. Understanding the barriers and bottlenecks that could delay the incorporation of these technologies may be useful for the NTCP stakeholders. In Brazil, several public health programs [8-12], including DOTS [13], had their implementation process investigated. However, no published studies on the implementation process of the recently adopted therapeutic regimen for tuberculosis were found in the literature.

The objective of the present study is to investigate sociodemographic, epidemiological and operational factors associated with the implementation process of the FDC-RHZE regimen for tuberculosis treatment in Brazilian municipalities. The understanding of this process may identify areas with poor adhesion to the new intervention and eventually guide the $\mathrm{MoH}$ in future implementation of health programs and policies in the country.

\section{Methods}

The analysis unit of this ecological study is the Brazilian municipalities. Data from the Brazilian Case Notification Database (SINAN-Tuberculosis) were used. All municipalities with at least one tuberculosis case notified at SINAN were considered eligible. Population size estimates were those calculated by the Brazilian Geography and Statistics Institute (IBGE) and are available on the Informatics Department of the Brazilian National Health System's website (www.datasus.gov.br). Patient records from SINAN database include which drugs were used but not the regimen (i.e., whether FDC was in use). Thus, new adolescent and adult (>10 years) cases notified between December 2009 and March 2011 using the four drugs (R, H, Z and E) after the starting month of implementation of the FDCRHZE, as informed by the State Health Secretaries, were considered as users of the new FDC-RHZE regimen. We performed an initial quality evaluation on this data frame, aiming to identify data completeness, errors and inconsistencies. We concluded that the database was adequate for the present analysis [7].

The following epidemiological and demographic municipal explanatory factors were analyzed: $i$ - population size, $i i$ population density and iii- tuberculosis incidence (absolute number of cases and notification rate). Operational health unit explanatory factors included other NTCP recommendations [1]: $i$ - use of directly observed treatment (DOT-), $i i-$ bacteriological confirmation of cases (positive sputum smear or culture for M. tuberculosis) and iii- bacteriologic monitoring of treated cases (monthly sputum smear). We initially evaluated two outcomes: $i$ - period of onset of the new regimen implementation and ii- implementation speed, i.e., the duration of time until maximum coverage $(100 \%)$ of the new regimen was reached. After an initial exploratory analysis with three ranges ( $\leq 2$ months, $2-4$ months and $\geq 4$ months), we chose to work with a 3 month cut-off. Rapid implementation was defined as up to three months ( $\leq 3$ months) from the onset to maximum coverage. This period can be considered adequate for the Brazilian health system based on its decentralized structure.

Exploratory data analysis also evaluated the distribution of the socio-demographic, epidemiological and operational health service performance variables. We used the odds ratio (OR) to compare the groups of interest. We obtained crude and adjusted estimates in single and multiple regression models using the STATA 10.0 software [14]. The $95 \%$ confidence intervals (CI) was calculated using the Mantel-Hanszel method. Explanatory variables with a marginal association with the outcome $(p \leq 0.20)$ in the bivariate analysis were included into the multiple regression model.

This study was approved by the Institutional Review Board of the Social Medicine Institute (process $\mathrm{n}^{\circ}$ 0024.0.259.000-11) and by the National Committee of Ethics in Research (CONEP, process $\left.n^{\circ} 16776\right)$.

\section{Results}

The municipalities' characteristics are described in Table 1. Sixty-nine percent $(3,826)$ of Brazilian municipalities were included. Over $70 \%$ implemented the new regimen between the $4^{\text {th }}$ quarter of 2009 and the $1^{\text {st }}$ quarter of 2010; $45 \%$ reached maximum coverage in less than two months (Table 1).

Few municipalities (2\%) have more than 250,000 inhabitants, one-fifth have a high population density (over 88 inhabitants per $\mathrm{km}^{2}$ ) and the same proportion has a density lower than 11 inhabitants per $\mathrm{km}^{2}$.

Most of the municipalities had a low or intermediate incidence rate. Noteworthy, more than $90 \%$ of municipalities 
Table 1 Characteristics of the municipalities that implemented the FDC-RHZE regimen in Brazil

\begin{tabular}{|c|c|c|}
\hline Characteristics & n & $\%$ \\
\hline \multicolumn{3}{|c|}{$\begin{array}{l}\text { Time to achieve maximum coverage by the FDC-RHZE } \\
\text { regimen }\end{array}$} \\
\hline Less than 2 months & 1722 & 45.0 \\
\hline 2 to 4 months & 599 & 15.7 \\
\hline More than 4 months & 1505 & 39.3 \\
\hline \multicolumn{3}{|c|}{ Period of onset of the FDC-RHZE regimen implementation } \\
\hline $4^{\text {th }}$ quarter 2009 to $1^{\text {st }}$ quarter 2010 & 2734 & 71.5 \\
\hline $2^{\text {nd }}$ quarter 2010 to $3^{\text {rd }}$ quarter 2010 & 734 & 19.2 \\
\hline $4^{\text {th }}$ quarter 2010 to $1^{\text {st }}$ quarter 2011 & 358 & 9.3 \\
\hline \multicolumn{3}{|l|}{ Population of municipalities } \\
\hline Less than 10,000 inhabitants & 1062 & 27.8 \\
\hline $10,000-50,000$ inhabitants & 2156 & 56.3 \\
\hline $50,000-250,000$ inhabitants & 509 & 13.3 \\
\hline 250,000-500,000 inhabitants & 61 & 1.6 \\
\hline More than 500,000 inhabitants & 38 & 1.0 \\
\hline \multicolumn{3}{|l|}{ Classification of the population density } \\
\hline Less than 11 inhabitants $/ \mathrm{km}^{2}$ & 817 & 21.4 \\
\hline $11-22$ inhabitants $/ \mathrm{km}^{2}$ & 736 & 19.2 \\
\hline $22-44$ inhabitants $/ \mathrm{km}^{2}$ & 906 & 24.0 \\
\hline 44-88 inhabitants $/ \mathrm{km}^{2}$ & 609 & 16.0 \\
\hline More than 88 inhabitants $/ \mathrm{km}^{2}$ & 755 & 19.4 \\
\hline \multicolumn{3}{|l|}{ Level of incidence } \\
\hline Very low $<10 / 100,000$ & 523 & 13.7 \\
\hline Low 10-25/100,000 & 1081 & 28.2 \\
\hline Intermediate $25-50 / 100,000$ & 1329 & 34.7 \\
\hline High 50-100/100,000 & 667 & 17.4 \\
\hline Very high >100/100,000 & 226 & 6.0 \\
\hline \multicolumn{3}{|l|}{ Proportion of cases in $\mathrm{DOT}^{*}$} \\
\hline Very low <20\% & 114 & 3.0 \\
\hline Low $20-40 \%$ & 36 & 1.0 \\
\hline Intermediate $40-60 \%$ & 55 & 1.4 \\
\hline High 60-80\% & 88 & 2.3 \\
\hline Very high >80\% & 3533 & 92.3 \\
\hline \multicolumn{3}{|l|}{ Laboratory confirmation of diagnosis } \\
\hline Very low $<20 \%$ & 574 & 15.0 \\
\hline Low $20-40 \%$ & 323 & 8.4 \\
\hline Intermediate $40-60 \%$ & 672 & 17.5 \\
\hline High 60-80\% & 784 & 20.5 \\
\hline Very high >80\% & 1473 & 38.6 \\
\hline \multicolumn{3}{|l|}{ Laboratory monitoring } \\
\hline Very low <20\% & 983 & 25.7 \\
\hline Low $20-40 \%$ & 310 & 8.2 \\
\hline Intermediate 40-60\% & 567 & 14.8 \\
\hline High 60-80\% & 633 & 16.5 \\
\hline Very high > $>00 \%$ & 1333 & 34.8 \\
\hline
\end{tabular}

have a very high proportion (more than $80 \%$ ) of cases under DOT (Table 1).

Over half of the municipalities perform laboratory confirmation for tuberculosis in more than $60 \%$ of diagnosed cases. As for laboratory monitoring of treated cases, $34 \%$ perform in less than $40 \%$ of cases and a similar proportion in more than $80 \%$ of cases (Table 1).

Because the onset date of implementation did not have a clear trend, and no relationship was detected between the explanatory factors and the onset of the implementation (data not shown), only rapid implementation was analyzed as the outcome in the present study.

Table 2 presents demographic, epidemiological and operational performance characteristics according to the time to reach maximum coverage of the new RHZEFDC regimen. The more populated the municipalities are, the longer it takes to reach maximum coverage. Conversely, the higher the demographic density and incidence rates, the slower the implementation. Based on this exploratory analysis, the cut-off points of the independent variables were set as shown in Table 3 .

Operational health service performance characteristics, such as more laboratory confirmation and monitoring of cases, were associated with a more rapid implementation. However, the inverse relationship occurs for the proportion of cases under DOT (Table 2). In the multivariate context, the association between speed and laboratory monitoring has lost statistical significance (Table 3). The variable "high laboratory monitoring ( $>80 \%)$ " was not associated in the multiple regression analysis. Thus, it was excluded from the final model.

\section{Discussion}

The understanding of the process of adoption of any new health technology becomes highly important for tuberculosis services as new diagnostic tests [15], treatment regimens [16] and vaccines [17] are expected to emerge in the next few years, after decades of stagnation. How to evaluate these processes, however, is a challenge. Habicht et al. (1999) [18] revised the design options to evaluate public health program performance. They enumerate, as indicators of performance: adequacy, provision, utilization, coverage and impact. The authors also point out that specific interventions should be evaluated considering the initially planned implementation schedule. In the present study, we chose to analyze the time till full coverage of the implementation of a new treatment recommendation in different municipalities in Brazil using secondary data. This was only possible because notification of tuberculosis is mandatory in the country.

Elmahalli et al. (2010) [19] assessed the implementation of DOTS strategy in two chest facilities in Alexandria, Egypt, using treatment success as the outcome. They argue that operational indicators, such as treatment 
Table 2 Epidemiological characteristics and NTP performance according to the time to full implementation of the FDCRHZE regimen in Brazil

\begin{tabular}{|c|c|c|c|c|}
\hline \multirow[t]{2}{*}{ Characteristics } & \multicolumn{4}{|c|}{ Time to full implementation of FDC-RHZE regimen in Brazil } \\
\hline & Less than 2 months & 2 to 4 months & More than 4 months & Total \\
\hline \multicolumn{5}{|l|}{ Demographic and epidemiological } \\
\hline Size population (mean) & 11756 & 17941 & 98974 & 47032 \\
\hline Population density (mean) & 35.2 & 46.4 & 313.2 & 146.4 \\
\hline Tuberculosis incidence rate* 2010 (mean) & 25.3 & 32.2 & 67.3 & 42.9 \\
\hline \multicolumn{5}{|l|}{ Operational NTP** } \\
\hline Proportion of patients with $\mathrm{DOT}^{* * *}$ (mean) & 96.4 & 95.5 & 92.4 & 94.7 \\
\hline Proportion of patients with confirmatory laboratory tests (mean) & 60.6 & 62.7 & 64.6 & 62.5 \\
\hline Proportion of patients with follow-up laboratory tests (mean) & 49.6 & 59.0 & 59.6 & 55.0 \\
\hline
\end{tabular}

* Rate per 100 hundred inhabitants; **NTP-National tuberculosis program; ***DOT-directly observed treatment.

outcome, can be considered excellent tools for monitoring the process of tuberculosis care, especially in developing countries. Although we agree that these are useful indicators of program performance, they are less appropriate to study the implementation process of a new recommendation. In our study, we preferred, instead, to study the implementation process of the new treatment regimen using a different approach, since other relevant data were available in the Brazilian surveillance system.

The implementation of new tuberculosis treatments, including MDR-TB treatment, was reported in different countries [20]. However, these analyses were essentially descriptive. To our knowledge, there are no previous studies addressing factors associated with the implementation process measured as the time to reach full coverage. In the present study, we addressed the factors associated with the time to full coverage of new regimen implementation process. Almost $70 \%$ of Brazilian municipalities had notified at least one case of tuberculosis in the study period, which reflects on one hand, the extent of the disease in the country and on the other hand, the expansion of tuberculosis diagnostic activities. Demographic and epidemiological

Table 3 Factors associated with a short time ( $\leq 3$ months) to full implementation of the FDC-RHZE regimen in Brazil

\begin{tabular}{|c|c|c|c|c|}
\hline Factors & Crude odds ratio & $95 \% \mathrm{Cl}$ & Adjusted odds ratio & $95 \% \mathrm{Cl}$ \\
\hline \multicolumn{5}{|c|}{ Small population $(<10,000)$} \\
\hline No & 1 & & 1 & \\
\hline Yes & 16.84 & $13.39-21.17$ & 25.52 & 19.09- 34.10 \\
\hline \multicolumn{5}{|c|}{ Low population density (<88 inhabitants $/ \mathrm{km}^{2}$ ) } \\
\hline No & 1 & & 1 & \\
\hline Yes & 5.64 & $4.68-6.80$ & 2.33 & $1.87-2.91$ \\
\hline \multicolumn{5}{|c|}{ Low level of incidence TB $(<50 / 100,000)$} \\
\hline No & 1 & & 1 & \\
\hline Yes & 4.21 & $3.57-4.96$ & 8.79 & $6.75-11.45$ \\
\hline \multicolumn{5}{|c|}{ High coverage DOT* (>80\%) } \\
\hline No & 1 & & 1 & \\
\hline Yes & 2.30 & $1.79-2.95$ & 1.55 & $1.14-2.12$ \\
\hline \multicolumn{5}{|c|}{ High laboratory confirmation pulmonary TB (>80\%) } \\
\hline No & 1 & & 1 & \\
\hline Yes & 2.12 & $1.85-2.42$ & 1.93 & $1.63-2.29$ \\
\hline \multicolumn{5}{|c|}{ High laboratory monitoring (>80\%) } \\
\hline No & 1 & & 1 & \\
\hline Yes & 1.45 & $1.27-1.67$ & 0.92 & $0.78-1.09$ \\
\hline \multicolumn{5}{|c|}{ Less than 120 patients treated } \\
\hline No & 1 & & 1 & \\
\hline Yes & 134.26 & $18.73-962.41$ & 10.07 & $1.36-74.52$ \\
\hline
\end{tabular}

* DOT- Directly observed treatment. 
factors as well as operational factors influenced rapid implementation. Among them, demographic factors had the higher magnitude of association. Municipalities characteristics such as population size, demographic density and incidence rates were associated with the rapid implementation of the new regimen. Although in a smaller magnitude, compliance to some NTCP recommendations, such as DOT and microbiological confirmation of cases, also were associated with rapid implementation.

Larger municipalities generally have health systems with many facilities, which need more human resources and health infrastructure, more complex public health program management. They also have populations with a high heterogeneity concerning access to diagnosis and tuberculosis treatment services, which may explain the more rapid implementation in smaller municipalities. This explanation is corroborated by a recent study in Recife, a large city in the Northeast of Brazil, where the incomplete implementation of the epidemiological surveillance management was explained by lack of human resources and incipient performance of planning and Monitoring \& Evaluation activities [21]. Likewise, the Family Health Program implementation in Santa Catarina, a wealthy and developed state in Southern Brazil, was firstly implanted in areas less assisted, in small or medium size municipalities, where financial incentive to the program induced rapid implementation. Indeed, one or two family health teams offers high coverage rates in municipalities with up to 10,000 inhabitants [22].

Regardless of the population size, demographic density also delayed the implementation of the new treatment. Poor social condition found in situations of intense urban agglomerations possibly hamper access to health services. It is intuitive to expect that municipalities with small populations or a small number of cases have easier access to new regimens. Areas with large number of cases demand more health units and higher number of trained professionals. On the other hand, higher incidence rates are usually found in situations of worse health policy performance. Lack of professionals, transport problems and insufficient resources for technical assistance were considered the major barriers for tuberculosis control in São José do Rio Preto, a medium size municipality [22].

In the present study, operational indicators such as DOT coverage and microbiological confirmation of diagnosis, as recommended by the NTCP guidelines, were independently associated to rapid implementation of the new regimen. This may reflect willingness, commitment and capacity of municipal TCP in lining-up with new recommendations from the NTCP. None of those different operational aspects represent by themselves a construct regarding the quality of tuberculosis control actions practiced at the municipal level. However, the independent association of those factors indicates that they evaluate different aspects of the same commitment.

Other factors possibly associated with rapid implementation of the new regimen, mainly those related to health service organization (human resources, decentralization of care, municipal tuberculosis control program structure among others), were not considered due to the nature of this study, which used secondary data from the tuberculosis surveillance system. The quality of this database may have influenced the results of this study. Thus, a previous evaluation was done to ensure the quality of the data [7]. Other possible limitations of this study may result from classification of individuals regarding the use of the new regimen, which was based on the use of 4 drugs in new cases, instead of the use of FDCs, since the latter information is not available. This may have overestimated the coverage of the new regimen, but is not likely to have influenced the evaluation of the implementation speed.

\section{Conclusions}

The analysis of the Brazilian surveillance secondary database made possible the evaluation of the implementation process of a new tuberculosis treatment regimen in this continental-sized country, measured by the length of time to reach full coverage. This analytical approach is useful to learn lessons. It was possible to demonstrate that demographic and operational characteristics of municipalities have influenced the implementation process. Municipalities with larger population size, higher demographic density and higher incidence rates may need more attention for the implementation of future new guidelines for tuberculosis control as well as for other diseases. Effectiveness studies are necessary and may be performed using the same methodology.

Competing interests

The authors declare they have no competing interests.

\section{Authors' contributions}

JUB conceived the study, analysed data and drafted the manuscript. DAC analysed data and helped drafting the manuscript. AT analysed data and drafted the manuscript. All authors read and approved the final manuscript.

\section{Acknowledgements}

Supported by the Ataulpho de Paiva Foundation, through a grant $(\mathrm{OPGH}$ 5254) by the Bill and Melinda Gates Foundation. AT has a research grant by CNPq. We acknowledge Draurio Barreira, coordinator of the Brazilian NTP for allowing access to the tuberculosis database and Alexandre Menezes for his review comments. None of the mentioned funding agencies are responsible for the statements in this article.

\section{Author details}

Professor Helio Fraga Reference Center, National School of Public Health, Fiocruz, Rio de Janeiro, Brazil. ${ }^{2}$ Social Medicine Institute, Rio de Janeiro State University, Rio de Janeiro, Brazil. ${ }^{3}$ Health Education Post-graduation Program, Gama Filho University, Rio de Janeiro, Brazil. ${ }^{4}$ Montreal Chest Institute, McGill University, Montreal, Canada.

Received: 30 August 2012 Accepted: 3 April 2013

Published: 9 April 2013 


\section{References}

1. Brasil: Manual de recomendações para o controle da tuberculose no Brasil. Braślia: Ministério da Saúde; 2011.

2. Gazetta CE, Vendramini SH, Ruffino-Netto A, Oliveira MR, Villa TC: Descriptive study of the implementation and impact of the directly observed treatment, short-course strategy in the Sao Jose do Rio Preto municipal tuberculosis control program (1998-2003). J Bras Pneumol 2007, 33(2):192-198.

3. Gerald LB, Bruce F, Brooks CM, Brook N, Kimerling ME, Windsor RA, et al: Standardizing contact investigation protocols. Int J Tuberc Lung Dis 2003, 7(12 Suppl 3):S369-S374.

4. BRASIL, Saude Md. Apresentação PNCT; 2011. [cited 2012 July 18 2012]; Available from: http://portal.saude.gov.br/portal/arquivos/pdf/ apres_padrao_25_01_11_site.pdf.

5. Brasil: Nota técnica sobre as mudanças no tratamento da tuberculose no Brasil para adultos e adolescentes. Norma técnica. Brasília: Ministério da Saúde/ Secretaria de Vigilância em Saúde/ Departamento de Vigilância Epidemiologica/ Programa Nacional de Controle da Tuberculose; 2009.

6. WHO: Global tuberculosis control: WHO report 2011. Geneve: World Health Organization; 2012. Report No.: WHO/HTM/TB/2011.16.

7. Braga J, Conceição D, Schlussel M, Loureiro R: Relatório técnico - Estudo da efetividade e da aceitabilidade do tratamento da tuberculose com o esquema 4 em 1 DFC (Dose Fixa Combinada). CEPESC - UERJ: Rio de Janeiro; 2011.

8. Felisberto E, Carvalho EF, Maggi RS, Samico I: Avaliação do processo de implantação da estratégia da Atenção Integrada às doenças prevalentes da infância no Programa Saúde da Família, no estado de Pernambuco, Brasil. Cadernos de saude publica / Ministerio da Saude, Fundacao Oswaldo Cruz, Escola Nacional de Saude Publica 2002, 18:1737-1745.

9. Felisberto E, Freese E, Alves CKA, Bezerra LCA, Samico I: Política de monitoramento e avaliação da atenção básica no Brasil de 2003 a 2006: contextualizando sua implantação e efeitos. Rev bras saúde matern infant 2009, 9(3):339-357.

10. Henrique F, Calvo MCM: Grau de implantação do Programa Saúde da Família e indicadores sociais. Cienc Saude Coletiva 2009, 14(sup 1):1359-1365.

11. Nagahama EEl: Avaliação da implantação de serviços de saúde reprodutiva no Município de Maringá, Paraná. Brasil Cad saúde pública 2009, 25(Sup 2):S279-S290.

12. Quinino LRM, Costa JMBS, Aguiar LR, Wanderley TNG, Barbosa CS: Avaliação das atividades de rotina do Programa de Controle da Esquistossomose em municípios da Região Metropolitana do Recife, Pernambuco, entre 2003 e 2005. Epidemiologia e Serviços de Saúde 2009, 18(4):335-343.

13. de Sa LD, de Andrade MN, Nogueira Jde A, Villa TC, de Figueiredo TM, de Queiroga RP, et al: Implantacao da estrategia DOTS no controle da Tuberculose na Paraiba: entre o compromisso politico e o envolvimento das equipes do programa saude da familia (1999-2004). [Implementation of the DOTS strategy in the control of TB in Paraiba: between the political commitment and the involvement of the teams of the family health program (1999-2004)]. Cien Saude Colet 2011, 16(9):3917-3924.

14. StataCorp LP: Stata graphics reference manual: release 10 College Station. Texas: StataCorp LP; 2007 (College Station is a city in Brazos County, Texas).

15. Cobelens F, van den Hof S, Pai M, Squire SB, Ramsay A, Kimerling ME: Which new diagnostics for tuberculosis, and when? The Journal of infectious diseases 2012, 205(Suppl 2):S191-198.

16. Gardner CA, Acharya T, Pablos-MÃOndez A: The global alliance for tuberculosis drug development--accomplishments and future directions. 2005, 26(2):341.

17. Kaufmann SHE, Hussey G, Lambert PH: New vaccines for tuberculosis. Lancet 2010, 375(9731):2110-2119.

18. Habicht JP, Victora CG, Vaughan JP: Evaluation designs for adequacy, plausibility and probability of public health programme performance and impact. Int J Epidemiol 1999, 28(1):10-18.

19. Elmahalli AA, Abdel-Aziz BF: Assessment of the implementation of DOTS strategy in two chest facilities in Alexandria, Egypt. Eastern Mediterranean health journal $=$ La revue de sante de la Mediterranee orientale = al-Majallah al-sihhiyah li-shara al-mutawassit 2007, 13(5):1085-97.

20. Furin J, Bayona J, Becerra M, Farmer P, Golubkov A, Hurtado R, et al: Programmatic management of multidrug-resistant tuberculosis: models from three countries. Int J Tuberc Lung Dis 2011, 15(10):1294-300.
21. Bezerra LC, Freese E, Frias PG, Samico I, Almeida CK: Epidemiological surveillance at the municipal level: evaluation of the degree of implementation. Cad Saude Publica 2009, 25(4):827-839.

22. Nogueira JdA, Ruffino-Netto A, Villa TCS, Monroe AA, Lucca MES: Implantação da estratégia DOTS no controle da tuberculose em Ribeirão Preto, São Paulo (1998-2004). Boletim de Pneumologia Sanitária 2006, 14(3): 141-144.

doi:10.1186/1471-2458-13-321

Cite this article as: Braga et al:: Factors associated with the rapid implementation process of the fixed-dose combination RHZE tuberculosis regimen in brazil: an ecological study. BMC Public Health 2013 13:321.

\section{Submit your next manuscript to BioMed Central and take full advantage of:}

- Convenient online submission

- Thorough peer review

- No space constraints or color figure charges

- Immediate publication on acceptance

- Inclusion in PubMed, CAS, Scopus and Google Scholar

- Research which is freely available for redistribution 